\title{
The Incidence Rate of Colorectal Cancer in Saudi Arabia: An Observational Descriptive Epidemiological Analysis
}

This article was published in the following Dove Press journal: International Journal of General Medicine

\author{
Ahmad Almatroudi (D) \\ Department of Medical Laboratories, \\ College of Applied Medical Sciences, \\ Qassim University, Buraydah 5I452, Saudi \\ Arabia
}

Introduction: Colorectal cancer (CRC) is the third most commonly diagnosed malignancy and its incidence, as well as mortality rate, is increasing globally. In this paper, the epidemiological analysis of CRC which includes colon cancer (CC) and rectum cancer (RC) is done among the Saudi Arabian population based on the registered cases in the Saudi cancer registry between 2006 and 2016. The study describes the crude incidence rates (CIRs) and age-standardized incidence rates (ASIRs) of colorectal cancer by year of diagnosis, age group, and administrative regions to explore the spread, distribution, trend, and factual state of the disease in Saudi Arabia.

Methodology: For statistical analysis of data, $t$-test, sex ratio, descriptive statistics, and Kruskal-Wallis were done using IBM Statistical Package for the Social Sciences version 20.0 (SPSS). A total of 7849 and 5164 of colorectal cancer and rectum cancer cases were reported from January 2006 to December 2016, respectively.

Results: Results displayed that $\mathrm{CRC}$ is more frequent in males than females and have a high mean number and percentage in the old age group (60-75 and above). Riyadh (for CC and RC), Makkah (CC), and Eastern Province (RC) showed the highest mean CIR and ASIR for males. The highest CIR sex ratio was calculated in Jouf and Madinah for CC whereas Qassim, Jazan, and Tabuk were calculated highest for RC. Highest ASIR sex ratio reported in Jouf (CC) and Tabuk (RC). Lowest CIR and ASIR among males were reported in Baha (CC) and northern region (RC). In females, the highest mean CIR and ASIR were reported in Riyadh (CC and RC) and Makkah (CC). Lowest CIR and ASIR among females were reported in Jazan in both CC and RC.

Conclusion: Regions of Eastern Province, Northern Region, and Jouf showed the most significant changes of CIRs and ASIRs for both cancers, whereas the least significant change was reported in Jazan from 2006 to 2016.

Keywords: epidemiological analysis, colorectal cancer, Saudi cancer registry, CIR, ASIR, statistical analysis

\section{Introduction}

Cancer is the second utmost recurrent cause of death all around the world. The International Agency for Research on Cancer (IARC) estimated that, globally, nearly 18.07 million new cases of cancer and approx. 9.5 million deaths from cancer occurred. ${ }^{1}$ Colorectal cancer (CRC) (includes colon cancer and rectal cancer) is the third most common cancer globally after lung and breast cancer (Table 1). ${ }^{2}$ In $2018,0.88$ million deaths were estimated worldwide. ${ }^{3}$ CRC occurring in developed regions like Europe,
Correspondence: Ahmad Almatroudi Department of Medical Laboratories, College of Applied Medical Sciences, Qassim University, Buraydah 5I452, Saudi Arabia

Email aamtrody@qu.edu.sa
International Journal of General Medicine 2020:13 977-990 
Table I Numbers, ASIR, ASMR, Crude Rates of Few Top GI and Non-GI Cancers in the World 1,3

\begin{tabular}{|l|l|l|l|l|l|l|}
\hline \multirow{2}{*}{ Cancer } & \multicolumn{2}{l}{ Incidence } & \multicolumn{2}{l|}{ Mortality } & \multicolumn{3}{l|}{} \\
\cline { 2 - 7 } & Number & ASIR & Crude Rate & Number & ASMR & Crude Rate \\
\hline All cancers & 18078957 & 197.9 & 236.9 & 9555027 & 101.1 & 125.2 \\
Breast Cancer & 2088849 & 46.3 & 55.2 & 626679 & 13.9 & 16.6 \\
Lung Cancer & 2093876 & 22.5 & 27 & 1761007 & 18.6 & 23.1 \\
Colorectal Cancer & 1849518 & 19.7 & 24.2 & 880792 & 8.9 & 11.5 \\
Stomach & 1033701 & 11.1 & 13.5 & 782685 & 8.2 & 10.3 \\
Liver & 841080 & 9.3 & 11 & 781631 & 8.5 & 10.2 \\
Oesophagus & 572034 & 6.3 & 7.5 & 508585 & 5.5 & 6.7 \\
Pancreas & 458918 & 4.8 & 6 & 432242 & 4.4 & 5.7 \\
\hline
\end{tabular}

America, and Australia as compared to the developing or less developed nations. ${ }^{4}$ However, in affluent countries, there is a considerable decrease in CRC incidence and mortality due to rapid screening and improved treatments. ${ }^{5,6}$ The countries with the highest age-standardized incidence rates (ASIRs) and age-standardization mortality rate (ASMRs) of CRC among all sexes were Austria, New Zealand, Mongolia, and Hungary respectively in $2018 .^{3}$ SEER Cancer statistics 2020, estimated approx. 147,950 new cases of colon and rectum cancer ( $8.2 \%$ of all new cancer cases) and estimated approx. 53,200 deaths ( $8.8 \%$ of all cancer deaths). ${ }^{6}$ Among the five major Gastrointestinal cancers, colorectal cancer is topmost cancer with high ASIR in all sexes worldwide (Table 1). ${ }^{1,7}$

In Saudi Arabia (SA), all cancer ASIR is 88.7 per 100,000 populations and ASMR is 43.3 per 100,000 populations, respectively. Colorectal cancer (ASIR- 13.1, ASMR$6.3)$ is the second most common cancer that occurred after breast cancer (ASIR- 27.3, ASMR-7.5) in Saudi Arabia. In Saudi males, colorectal cancer is the top most common cancer whereas it the third most common cancer among Saudi females. And out of five major GI tract cancer, colorectal is under the top ten cancers of Saudi Arabia. ${ }^{1,8}$ According to ICAR, WHO, GLOBOCON 2018, among gulf countries, the highest ASIR in both sexes, male and female were found in UAE, Saudi Arabia, and Kuwait, respectively, whereas the highest ASMR was found in Qatar and Oman (Table 2).

Obesity, ${ }^{9}$ diets rich in red and processed meat, alcohol consumption, smoking, inflammatory bowel disease are modifiable risk factors (60-65\% CRC rises sporadically) whereas family history or personal history of colorectal cancer and polyps in the colon (25-30\%), ulcerative colitis or Crohn's disease or hereditary syndromes (approx. 5\%) are non-modifiable risk factors. ${ }^{5,10}$ Westernization of a country, change in lifestyle and eating patterns, industrialization,
Table 2 Gulf Countries ASIRs and ASMRs of Colorectal Cancer in Males and Females, All Ages, 2018'

\begin{tabular}{|l|l|l|l|l|l|l|}
\hline \multirow{2}{*}{$\begin{array}{l}\text { Gulf } \\
\text { Countries }\end{array}$} & \multicolumn{2}{l|}{ Both Sexes } & \multicolumn{2}{l|}{ Male } & \multicolumn{2}{l|}{ Female } \\
\cline { 2 - 7 } & ASIR & ASMR & ASIR & ASMR & ASIR & ASMR \\
\hline Kuwait & 13.2 & 7.5 & 12.9 & 7.4 & 14 & 7.9 \\
Oman & 11 & 6.4 & 11.7 & 6.8 & 9.6 & 9.5 \\
Bahrain & 12.6 & 6.4 & 14.2 & 8.9 & 11.2 & 7.6 \\
Qatar & 13 & 8.7 & 13.5 & 9 & 13.8 & 9.5 \\
UAE & 14.1 & 7.4 & 14.8 & 7.7 & 13.5 & 7.3 \\
Saudi & 13.1 & 6.3 & 14.9 & 7.3 & 10.6 & 5 \\
Arabia & & & & & & \\
\hline
\end{tabular}

environment are some other factors that are responsible for the rise in the $\mathrm{CRC}$ incidence rate. ${ }^{4,5,11}$

In this article, aimed to study the epidemiological parameters of crude incidence rates (CIRs) and Agestandardized incidence rates (ASIRs) of colorectal cancer by year of diagnosis, age group, and administrative regions among the Saudi population to investigate and describe the distribution of colorectal cancer. For the purpose, an observational detailed epidemiological study of the distribution of colorectal cancer cases registered in the Saudi cancer registry between 2006 and 2016 was carried out.

\section{Materials and Methods}

A retrospective observational population-based epidemiological study of colorectal cancer was performed and the data is based on the cancer registry by the ministry of health, Saudi Arabia. ${ }^{12}$ The data of colon and rectum cancer diagnosed cases in all regions of Saudi Arabia between January 2006 and December 2016 is open to the public as well as easily accessible through the Saudi Cancer Registry (SCR) annual reports, ${ }^{13}$ hence, the ethical approval for this study was not required. SCR provides a comprehensive report for 13 administrative regions from 
2006 to 2016, incidence with the percentage of cases, CIR and ASIR, categorized by the administrative regions of Saudi Arabia, gender, and the year of diagnoses. This study includes only Saudis (citizens of Saudi Arabia) and not non-Saudi residents. ${ }^{13,14}$

Statistical Package for the Social Sciences (SPSS) version 20.0 (IBM Corporation, Armonk, NY, USA) was used for statistical analysis. The CIRs and ASIRs of the year 2006 to 2016 were reported from SCR reports and differences between them were calculated to examine the trends of colon and rectum cancers among males and females in different administrative regions of Saudi Arabia. This was achieved by using independent-samples $t$-test to compare the CIRs and ASIRs of colon and rectum cancer among males and females. Also, a nonparametric Kruskal-Wallis $H$-test was performed to correlate the CIRs and ASIRs of colorectal cancer between regions of Saudi Arabia. Also, the male to female ratio of colorectal cancer was calculated from the age-specific incidence rate (AIR), the CIR, and the ASIR classified by age group, year of diagnosis, and administrative regions. The inclusive distribution of the percentage of a stage of cancers ie localized stage (not invasive), regional stage (invasive to nearby organs and tissues), distant stage (distantly spread), and unknown stage of colorectal cancer among males and females were also calculated from 2006 to $2016 .{ }^{15}$

\section{Results}

\section{Colorectal Cancer Among Males}

A total of 4157 colon cancer (CC) and 2959 rectal cancer (RC) cases were reported between January 2006 and December 2016 in SCR reports. The incidence of the number of colon and rectum cancer cases increased marginally from 2006 to 2016 (Tables 3 and 4). There were 232 cases $(6 \%)$ of $\mathrm{CC}$ and 182 of $\mathrm{RC}(6 \%)$ reported in 2006 (Figure 1A and B). From 2006 to 2016, the number of $\mathrm{CC}$ and $\mathrm{RC}$ cases are increased, representing an increase of $8 \%$ and $7 \%$, respectively. The mean number and percentage of CC and RC from 2006 to 2016 among males was 374 and 269 cases (9\% CC and 9.1\% RC) per year. The mean number and percentage of $\mathrm{CC}$ and RC cases reported between 2006 and 2016, classified by age group, was calculated. The class width of the age groups was maintained at 5 years, starting from 0 to 4 , till 70-74, and over 75 years of age. From 2006 to 2016, males from 75 years and over age group were most frequently diagnosed with CRC. In CC, males with 75 years and over age group followed by $65-69$ years of age group,
Table 3 The Difference Between CIR and ASIR of Colon Cancer Between 2006 and 2016

\begin{tabular}{|c|c|c|c|c|c|}
\hline Region & Sex & $\begin{array}{l}\text { CIR/ } \\
\text { ASIR }\end{array}$ & 2006 & 2016 & Difference \\
\hline \multirow[t]{4}{*}{ Asir } & \multirow[t]{2}{*}{ Male } & CIR & 2.1 & 6 & 3.9 \\
\hline & & ASIR & 3.2 & 7.5 & 4.3 \\
\hline & \multirow[t]{2}{*}{ Female } & CIR & 2.1 & 4.9 & 2.8 \\
\hline & & ASIR & 3.5 & 5.9 & 2.4 \\
\hline \multirow[t]{4}{*}{ Baha } & \multirow[t]{2}{*}{ Male } & CIR & 1.3 & 2.8 & 1.5 \\
\hline & & ASIR & I.7 & 2.3 & 0.6 \\
\hline & \multirow[t]{2}{*}{ Female } & CIR & 0.6 & 5.1 & 4.5 \\
\hline & & ASIR & I & 4.4 & 3.4 \\
\hline \multirow[t]{4}{*}{ Jazan } & \multirow[t]{2}{*}{ Male } & CIR & 0.4 & 1.7 & 1.3 \\
\hline & & ASIR & 0.7 & 2.5 & 1.8 \\
\hline & \multirow[t]{2}{*}{ Female } & CIR & 0.6 & I & 0.4 \\
\hline & & ASIR & 0.7 & I.I & 0.4 \\
\hline \multirow[t]{4}{*}{ Madinah } & \multirow[t]{2}{*}{ Male } & CIR & 2.2 & 6.5 & 4.3 \\
\hline & & ASIR & 4 & 9 & 5 \\
\hline & \multirow[t]{2}{*}{ Female } & CIR & 3.5 & 2.5 & -1 \\
\hline & & ASIR & 5.7 & 3.5 & -2.2 \\
\hline \multirow[t]{4}{*}{ Hail } & \multirow[t]{2}{*}{ Male } & CIR & 3 & 1.9 & $-I . I$ \\
\hline & & ASIR & 3.8 & 2.3 & -1.5 \\
\hline & \multirow[t]{2}{*}{ Female } & CIR & 0.8 & 4.9 & 4.1 \\
\hline & & ASIR & 1.2 & 5.6 & 4.4 \\
\hline \multirow[t]{4}{*}{ Qassim } & \multirow[t]{2}{*}{ Male } & CIR & 2.4 & 5.8 & 3.4 \\
\hline & & ASIR & 3.8 & 7.9 & 4.1 \\
\hline & \multirow[t]{2}{*}{ Female } & CIR & 2.3 & 4.5 & 2.2 \\
\hline & & ASIR & 3.9 & 6.2 & 2.3 \\
\hline \multirow[t]{4}{*}{ Najran } & \multirow[t]{2}{*}{ Male } & CIR & 2.2 & 0.9 & -1.3 \\
\hline & & ASIR & 5.3 & 1.3 & -4 \\
\hline & \multirow[t]{2}{*}{ Female } & CIR & I.I & 2.8 & 1.7 \\
\hline & & ASIR & 1.8 & 3.6 & 1.8 \\
\hline \multirow[t]{4}{*}{ Jouf } & \multirow[t]{2}{*}{ Male } & CIR & 1.8 & 3.7 & 1.9 \\
\hline & & ASIR & 3 & 5.7 & 2.7 \\
\hline & \multirow[t]{2}{*}{ Female } & CIR & 1.2 & 2.7 & 1.5 \\
\hline & & ASIR & 3.4 & 4.6 & 1.2 \\
\hline
\end{tabular}

(Continued) 
Table 3 (Continued).

\begin{tabular}{|c|c|c|c|c|c|}
\hline Region & Sex & $\begin{array}{l}\text { CIR/ } \\
\text { ASIR }\end{array}$ & 2006 & 2016 & Difference \\
\hline \multirow[t]{4}{*}{ Tabuk } & \multirow[t]{2}{*}{ Male } & CIR & 1.5 & 3 & 1.5 \\
\hline & & ASIR & 3.7 & 4.9 & 1.2 \\
\hline & \multirow[t]{2}{*}{ Female } & CIR & 2.3 & 3.8 & 1.5 \\
\hline & & ASIR & 5 & 5.6 & 0.6 \\
\hline \multirow{4}{*}{$\begin{array}{l}\text { Northern } \\
\text { Region }\end{array}$} & \multirow[t]{2}{*}{ Male } & CIR & 3.2 & 2.1 & -1.1 \\
\hline & & ASIR & 4.9 & 3.5 & -1.4 \\
\hline & \multirow[t]{2}{*}{ Female } & CIR & 0.8 & 4.9 & 4.1 \\
\hline & & ASIR & 1.3 & 6.8 & 5.5 \\
\hline \multirow[t]{4}{*}{ Riyadh } & \multirow[t]{2}{*}{ Male } & CIR & 3.7 & 7.7 & 4 \\
\hline & & ASIR & 7.2 & 11.7 & 4.5 \\
\hline & \multirow[t]{2}{*}{ Female } & CIR & 3.4 & 5.7 & 2.3 \\
\hline & & ASIR & 6.9 & 9 & 2.1 \\
\hline \multirow[t]{4}{*}{ Makka } & \multirow[t]{2}{*}{ Male } & CIR & 3.1 & 5.3 & 2.2 \\
\hline & & ASIR & 5.3 & 6.3 & 1 \\
\hline & \multirow[t]{2}{*}{ Female } & CIR & 3 & 4.6 & 1.6 \\
\hline & & ASIR & 5 & 5.7 & 0.7 \\
\hline \multirow{4}{*}{$\begin{array}{l}\text { Eastern } \\
\text { Province }\end{array}$} & \multirow[t]{2}{*}{ Male } & CIR & 2.4 & 6.8 & 4.4 \\
\hline & & ASIR & 5.4 & 10.9 & 5.5 \\
\hline & \multirow[t]{2}{*}{ Female } & CIR & 3 & 5.2 & 2.2 \\
\hline & & ASIR & 5.5 & 7.9 & 2.4 \\
\hline
\end{tabular}

demonstrating $17 \%$ and $12 \%$ of all CC cases, respectively. Whereas in RC, 75 years aged men represent $14 \%$ and 65-69 years old men represent $12 \%$. The young age groups (aged 0-29 years range) documented the lowest average number and percentage of $\mathrm{CC}$ and $\mathrm{RC}$ cases (Figure 1A and B) (Supplementary Table 1. A, 1. B).

The mean age-specific incidence rate (AIR) of $\mathrm{CC}$ from 2006 to 2016 was highest in males of the age group of 75 years and over, followed by 70-74 and 65-6 age groups; whereas, in RC, it is highest in the age groups of 75 and over, 70-74, 65-69 and 60-64. The AIR sex ratio of $\mathrm{RC}$ was higher among males in all age groups, whereas in $\mathrm{CC}$ it was higher from 55 to 75 years and over. However, the AIR sex ratio was almost comparable to other age groups from 0 to 44 years (Figure $2 \mathrm{~A}$ and $\mathrm{B}$ ).
Table 4 The Difference Between CIR and ASIR of Rectum sCancer Between 2006 and 2016

\begin{tabular}{|c|c|c|c|c|c|}
\hline Region & Sex & $\begin{array}{l}\text { CIR/ } \\
\text { ASIR }\end{array}$ & 2006 & 2016 & Difference \\
\hline \multirow[t]{4}{*}{ Asir } & \multirow[t]{2}{*}{ Male } & CIR & 1.5 & 4.2 & 2.7 \\
\hline & & ASIR & 2.2 & 5.4 & 3.2 \\
\hline & \multirow[t]{2}{*}{ Female } & CIR & 1.6 & 2.1 & 0.5 \\
\hline & & ASIR & 2.7 & 2.3 & -0.4 \\
\hline \multirow[t]{4}{*}{ Baha } & \multirow[t]{2}{*}{ Male } & CIR & 3.2 & 1.7 & -1.5 \\
\hline & & ASIR & 4.6 & 2.2 & -2.4 \\
\hline & \multirow[t]{2}{*}{ Female } & CIR & 1.7 & 1.5 & -0.2 \\
\hline & & ASIR & 2 & 1.3 & -0.7 \\
\hline \multirow[t]{4}{*}{ Jazan } & \multirow[t]{2}{*}{ Male } & CIR & 0.8 & 1.2 & 0.4 \\
\hline & & ASIR & 1.2 & 1.4 & 0.2 \\
\hline & \multirow[t]{2}{*}{ Female } & CIR & 0 & 1.5 & 1.5 \\
\hline & & ASIR & 0 & 2 & 2 \\
\hline \multirow[t]{4}{*}{ Madinah } & \multirow[t]{2}{*}{ Male } & CIR & 2.4 & 2.5 & 0.1 \\
\hline & & ASIR & 3.9 & 3.5 & -0.4 \\
\hline & \multirow[t]{2}{*}{ Female } & CIR & 2.2 & 2.1 & -0.1 \\
\hline & & ASIR & 3.8 & 2.9 & -0.9 \\
\hline \multirow[t]{4}{*}{ Hail } & \multirow[t]{2}{*}{ Male } & CIR & 3.5 & 2.7 & -0.8 \\
\hline & & ASIR & 5 & 3 & -2 \\
\hline & \multirow[t]{2}{*}{ Female } & CIR & 1.2 & 3.7 & 2.5 \\
\hline & & ASIR & 1.8 & 4.6 & 2.8 \\
\hline \multirow[t]{4}{*}{ Qassim } & \multirow[t]{2}{*}{ Male } & CIR & 1.6 & 3.4 & 1.8 \\
\hline & & ASIR & 2.8 & 4.8 & 2 \\
\hline & \multirow[t]{2}{*}{ Female } & CIR & 0.7 & 1.8 & I.I \\
\hline & & ASIR & 1.3 & 2.4 & I.I \\
\hline \multirow[t]{4}{*}{ Najran } & \multirow[t]{2}{*}{ Male } & CIR & 0 & 1.4 & 1.4 \\
\hline & & ASIR & 0 & 1.9 & 1.9 \\
\hline & \multirow[t]{2}{*}{ Female } & CIR & 0.5 & 0 & -0.5 \\
\hline & & ASIR & 0.8 & 0 & -0.8 \\
\hline \multirow[t]{4}{*}{ Jouf } & \multirow[t]{2}{*}{ Male } & CIR & 0 & 2.1 & 2.1 \\
\hline & & ASIR & 0 & 3.2 & 3.2 \\
\hline & \multirow[t]{2}{*}{ Female } & CIR & 0 & 2.7 & 2.7 \\
\hline & & ASIR & 0 & 4.6 & 4.6 \\
\hline
\end{tabular}

(Continued) 
Table 4 (Continued).

\begin{tabular}{|c|c|c|c|c|c|}
\hline Region & Sex & $\begin{array}{l}\text { CIR/ } \\
\text { ASIR }\end{array}$ & 2006 & 2016 & Difference \\
\hline \multirow[t]{4}{*}{ Tabuk } & \multirow[t]{2}{*}{ Male } & CIR & 0.9 & 0.5 & -0.4 \\
\hline & & ASIR & 3 & 0.9 & -2.1 \\
\hline & \multirow[t]{2}{*}{ Female } & CIR & 0.3 & 0.6 & 0.3 \\
\hline & & ASIR & I.I & 0.6 & -0.5 \\
\hline \multirow{4}{*}{$\begin{array}{l}\text { Northern } \\
\text { Region }\end{array}$} & \multirow[t]{2}{*}{ Male } & CIR & 0 & 2.1 & 2.1 \\
\hline & & ASIR & 0 & 3.3 & 3.3 \\
\hline & \multirow[t]{2}{*}{ Female } & CIR & 0.8 & 0.7 & -0.1 \\
\hline & & ASIR & 1.7 & I.4 & -0.3 \\
\hline \multirow[t]{4}{*}{ Riyadh } & \multirow[t]{2}{*}{ Male } & CIR & 2.5 & 4.7 & 2.2 \\
\hline & & ASIR & 5.2 & 7.2 & 2 \\
\hline & \multirow[t]{2}{*}{ Female } & CIR & 2.7 & 3.6 & 0.9 \\
\hline & & ASIR & 5.4 & 5 & -0.4 \\
\hline \multirow[t]{4}{*}{ Makka } & \multirow[t]{2}{*}{ Male } & CIR & 2.5 & 4.1 & 1.6 \\
\hline & & ASIR & 4.2 & 5 & 0.8 \\
\hline & \multirow[t]{2}{*}{ Female } & CIR & 1.7 & 2.2 & 0.5 \\
\hline & & ASIR & 2.6 & 2.7 & 0.1 \\
\hline \multirow{4}{*}{$\begin{array}{l}\text { Eastern } \\
\text { Province }\end{array}$} & \multirow[t]{2}{*}{ Male } & CIR & 2.4 & 4.2 & 1.8 \\
\hline & & ASIR & 5.2 & 6.4 & 1.2 \\
\hline & \multirow[t]{2}{*}{ Female } & CIR & 1.8 & 4 & 2.2 \\
\hline & & ASIR & 3.5 & 5.7 & 2.2 \\
\hline
\end{tabular}

The crude incidence rates (CIRs) of CC and RC cases among males in Saudi Arabia indicate an increase with a slight decrease in 2008 and 2010 in CIR of both CC and RC (Supplementary Table 3. A, 3. B). In 2016, the CIR of 5.7 and 3.6 of $\mathrm{CC}$ and $\mathrm{RC}$ was the highest rate recorded by SCR. Additionally, the mean CIR of CC in males from 2006 to was 3.3 and for RC it was 2.8. We performed the independent-samples $t$-test on the CIRs among males and females and in results we found that the CIRs of CC [t (20) $=1.091, \mathrm{P}<0.01]$ and of $\mathrm{RC}[\mathrm{t}(20)=3.938, \mathrm{P}<0.01]$ were significantly higher in males than females. Besides, the mean CIR sex ratio for $\mathrm{CC}$ and $\mathrm{RC}$ was 1.1 and 1.3 respectively (Figure $3 \mathrm{~A}$ and $\mathrm{B}$ ).

The mean CIRs of CC and RC were categorized by the administrative regions of Saudi Arabia and were also reported from the SCR (Figure 4A and B). The regions of
Riyadh had the highest mean CIRs for CC and RC in males, respectively. Additionally, the second-highest CIRs were found in Makkah for $\mathrm{CC}$ and the Eastern region for RC in males. Since the data is not following a normal distribution, we performed the Kruskal-Wallis $H$-test on CIRs from all regions in males and found statistically significant for these regions in comparison to remaining administrative regions. The chi-square values $\left[\chi^{2}(12, \mathrm{~N}=143),(\mathrm{P}<0.01)\right]$ were calculated for $\mathrm{CC}\left(\chi^{2}=87.753\right)$ and $\mathrm{RC}\left(\chi^{2}=81.897\right)$ in per 100,000 males. Moreover, the highest CIR sex ratio was reported in Jouf at 1.5, and Madinah at 1.4 for CC. Whereas Qassim, Jazan, Makkah, and Tabuk showed the highest crude incidence male-to-female ratio for RC. The lowest mean CIR was observed for $\mathrm{CC}$ was Baha and $\mathrm{RC}$ was the Northern region (Figure $4 \mathrm{~A}$ and $\mathrm{B}$ ).

The ASIRs of CC and RC were reported from the SCR classified according to the year of diagnosis per 100,000 males (Figure 5A and B). Overall, the value of ASIRs of CC and RC are steadily increasing. In 2016, the highest ASIR of CC was reported at 7.8, and the lowest ASIR of $\mathrm{CC}$ was at 5.3 in 2008. Whereas, 2009 and 2016 were the years when the highest ASIR of RC was reported at 5.1 and the lowest ASIR of RC was reported in 2008 at 3.7. Furthermore, the mean ASIR of CC was at 6.3 and the mean ASIR of RC was at 4.5. We also performed the independent-sample t-tests on ASIRs of CC and RC among males and females and found that the ASIRs of $\mathrm{CC}[\mathrm{t}(20)=2.509, \mathrm{P}<0.01]$ and of $\mathrm{RC}[\mathrm{t}(20)=7.7$, $\mathrm{P}<0.01]$ were more significantly higher in males than females. On the other hand, the mean ASIR sex ratio from 2006 to 2016 per 100,000 was 1.1 for CC and 1.3 for RC.

The mean ASIRs of years 2006 to 2016 classified by the administrative region of Saudi Arabia for $\mathrm{CC}$ and $\mathrm{RC}$ were calculated (Figure 6A and B) (Supplementary Table 2. A, 2. B). The highest mean ASIR for CC was reported from the regions of Riyadh and Makkah, which was followed by the Eastern Province. Similarly, the highest mean ASIR for RC was reported from the region of Riyadh, followed by Eastern Province. We also performed the Kruskal-Wallis $H$-test on ASIRs from all regions in males and found statistically significant for these regions in comparison to remaining administrative regions (Supplementary Table 5. A, 5. B). The chi-square values $\left[\chi^{2}(12, \mathrm{~N}=143),(\mathrm{P}<0.01)\right]$ were calculated for $\mathrm{CC}\left(\chi^{2}=99.175\right)$ and $\mathrm{RC}\left(\chi^{2}=91.21\right)$. Likewise, the highest ASIR sex ratio was reported in Jouf for CC and Tabuk for RC. Alternatively, the lowest mean ASIRs of $\mathrm{CC}$ and $\mathrm{RC}$ was 


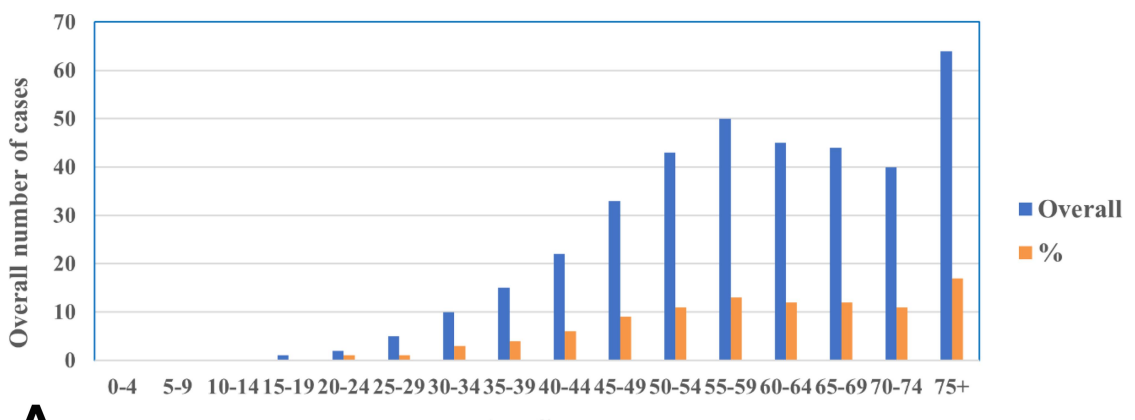

A

Age Group
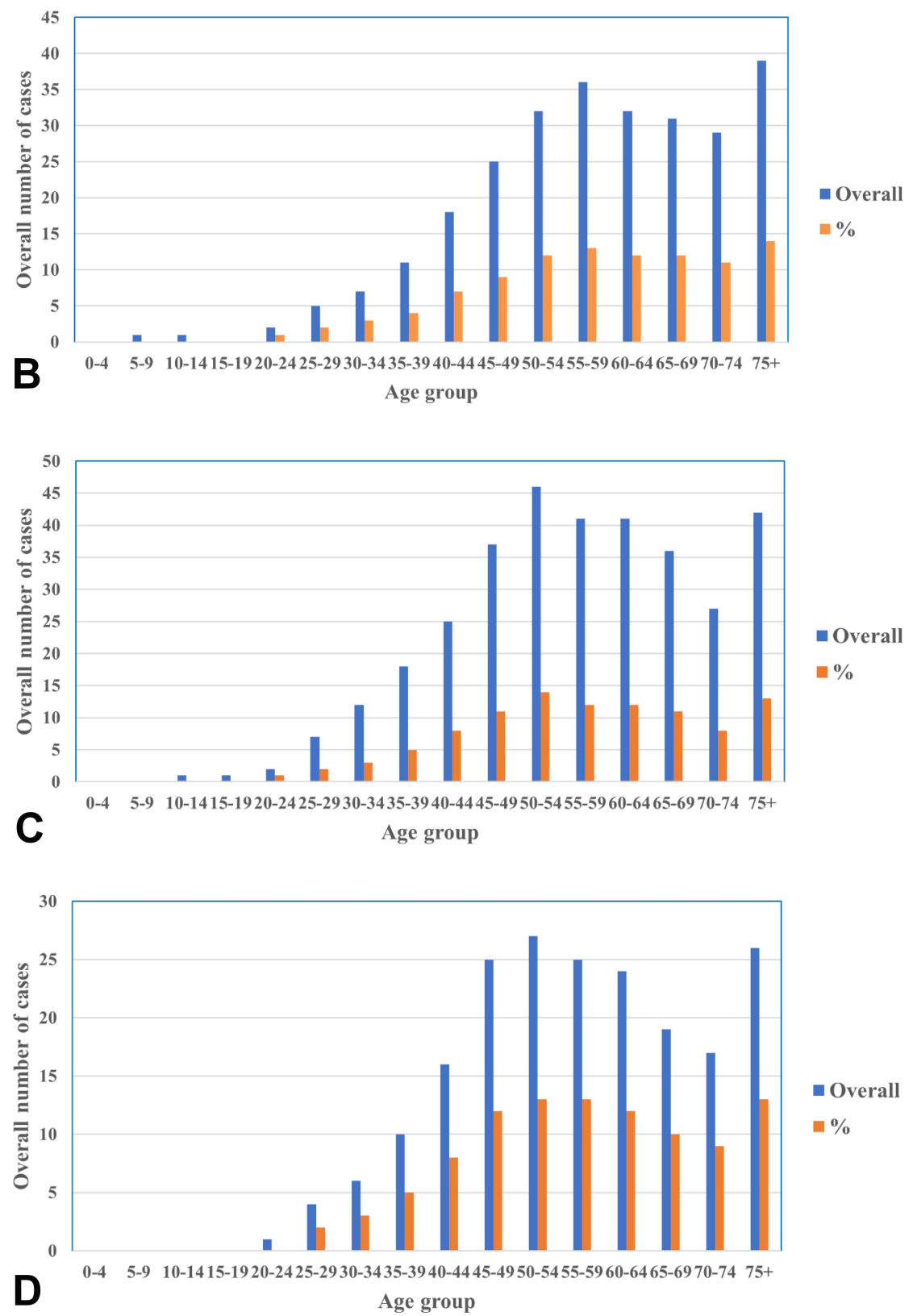

Figure I (A) Number and percentage of colon cancer in males during 2006 to 2016. (B) Number and percentage of rectum cancer in males during 2006 to 2016. (C) Number and percentage of colon cancer in females during 2006 to 2016. (D) Number and percentage of rectum cancer in females during 2006 to 2016. 

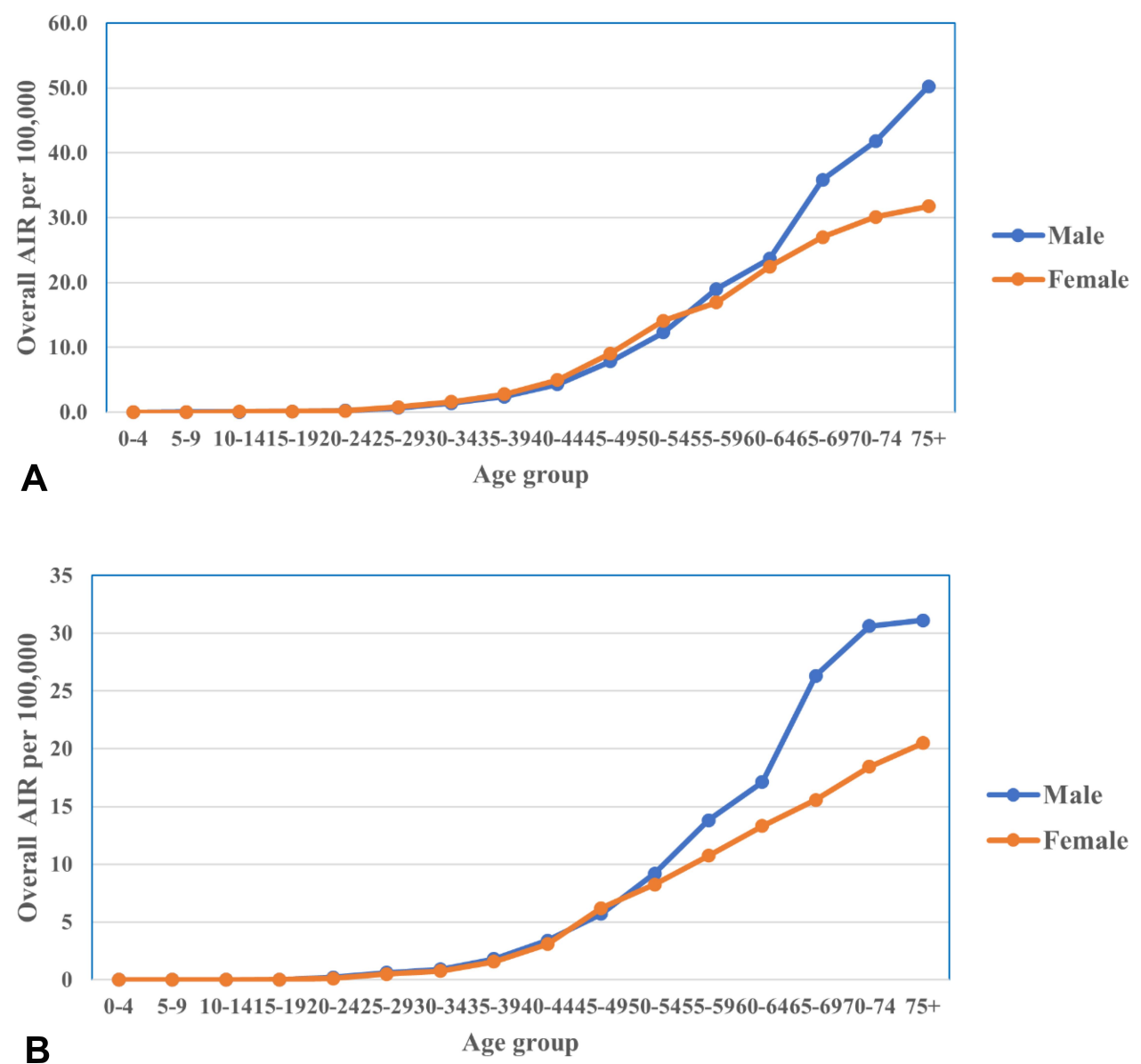

Figure 2 (A) Overall age-specific incidence rate (AIR) of colon cancer cases per 100,000 between males and females during 2006 to 2016. (B) Overall age-specific incidence rate (AIR) of rectum cancer cases per 100,000 between males and females during 2006 to 2016

documented in Baha, and the Northern region (Figure 6A and B).

The inclusive distribution of the percentage of a stage of colorectal cancer in males was reported to know that in what stage the cancer was diagnosed more frequently among males. We found that colorectal cancer was diagnosed more frequently at the regional stage (39.3\%), which was followed by a distant stage (25.7\%) and localized stage $(22.8 \%)$. It is also reported that colorectal cancer was diagnosed at an unknown stage in a lower percentage $(12.2 \%)$ (Figure 7A) (Supplementary Table 7. A).

\section{Colorectal Cancer Among Females}

A total of 3692 colon cancer (CC) and 2205 rectal cancer (RC) cases were reported between January 2006 and December 2016 in SCR reports (Supplementary Table 1. C, I, D). The incidence of the number of colon and rectum cancer cases increased from 2006 to 2016. There were 227 cases $(6 \%)$ of $\mathrm{CC}$ and 143 of RC (6\%) reported in 2006 (Figure $1 \mathrm{C}$ and $\mathrm{D}$ ). The number of $\mathrm{CC}$ and $\mathrm{RC}$ cases are increased, demonstrating an increase of $6 \%$ in both cancers. The mean number and percentage of $\mathrm{CC}$ and $\mathrm{RC}$ among females was 336 and 200 cases $(9.1 \%$ for both cancers $)$ per year. The mean number and percentage of $\mathrm{CC}$ and $\mathrm{RC}$ cases reported, classified by age group, were calculated. The class width of the age groups was maintained at 5 years, starting from 0 to 4, till 70-74, and over 75 years of age. Females from 50 to 54 years of age group were the most frequently diagnosed with CC demonstrating 14\% followed by 75 years and over, and 50-59 years of age groups, demonstrating $13 \%$ and $12 \%$ of the total number of $\mathrm{CC}$ cases, respectively. In RC, 50-54 years, 75 years and over, and 50-59 years of age groups females were the most frequently diagnosed and representing $13 \%$ followed by $60-64$ years and 45-49 years of age groups of females represent $12 \%$. In contrast, the lowest mean number and percentage of $\mathrm{CC}$ and $\mathrm{RC}$ were documented in the younger groups aged 0-19 years and 0-24 years, respectively (Figure 1C and D).

The mean age-specific incidence rate (AIR) of CC was the highest among females in the age group of 75 years 

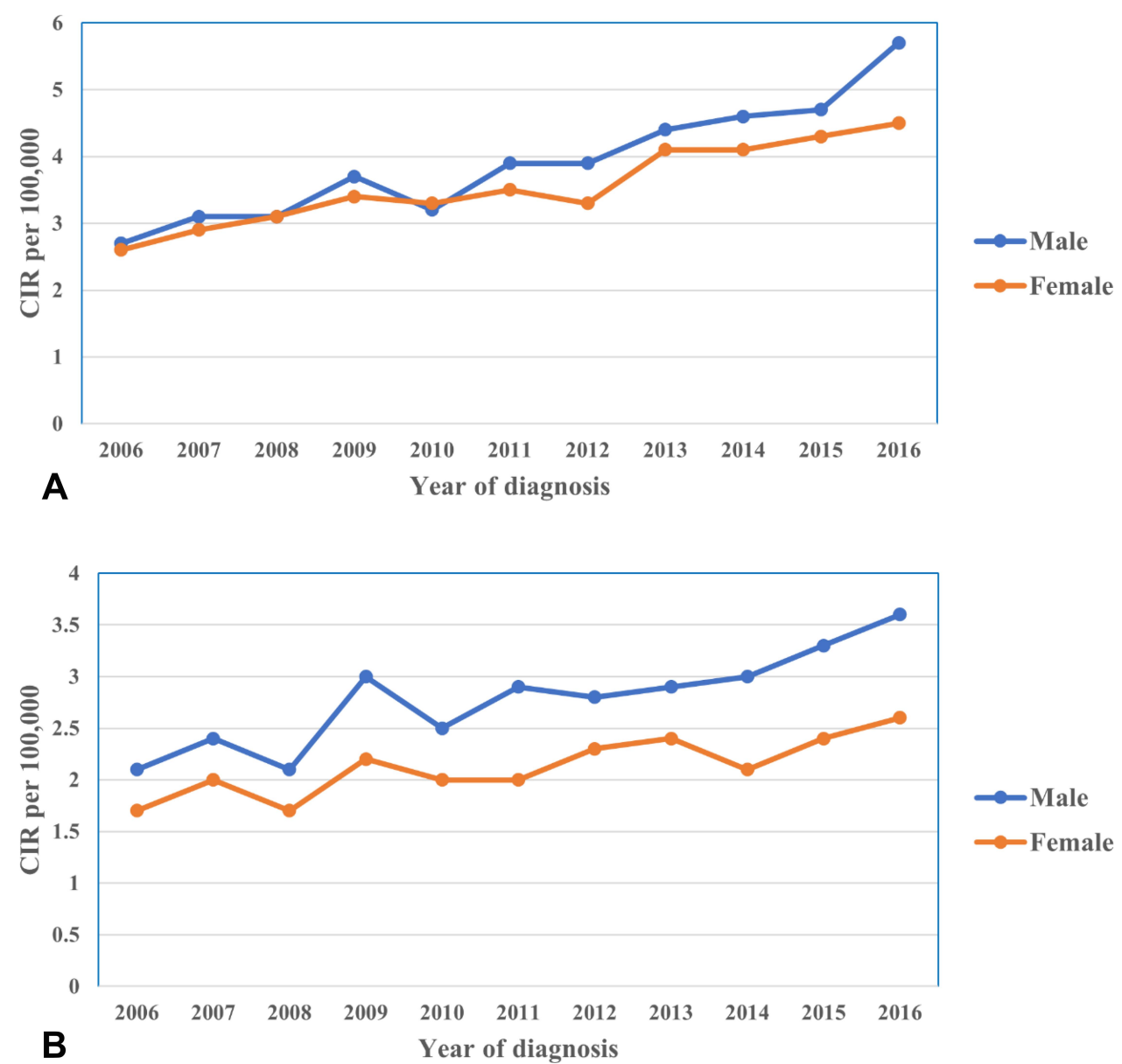

Figure 3 (A) Crude incidence rate (CIR) of colon cancer cases per 100,000 between males and females during 2006 to 2016. (B) Crude incidence rate (CIR) of rectum cancer cases per 100,000 between males and females during 2006 to 2016.

and over, followed by 70-74, 65-69, and 60-64; whereas in $\mathrm{RC}$, it is highest in the age group of 75 and over, followed by 70-74, 65-69 and 60-64 (Figure 2A and B) (Supplementary Table 3. A).

The crude incidence rates (CIRs) of CC cases amongst females in Saudi Arabia, classified by the year of diagnosis from 2006 to 2016 per 100,000 females, direct to a stable increase from 2006 to 2016, whereas, the CIRs of RC show a steady increase with a slight decrease in 2008 and 2014 (Figure 3A and B) (Supplementary Table 4. A, 4. B). The highest rate of CIR was reported in 2016 for CC and RC. The mean CIR among females from 2006 to 2016 of CC was 3.6 and of $\mathrm{RC}$ was 2.1 .

Furthermore, the mean CIRs of CC and RC in females were categorized by the administrative regions of Saudi Arabia and were also reported from the SCR (Figure 4A and B). The regions of Riyadh had the highest mean CIRs for $\mathrm{CC}$ and $\mathrm{RC}$ at 4.8 and 2.9, respectively. Additionally, the second-highest CIRs were found in Eastern Province in
$\mathrm{CC}$ and $\mathrm{RC}$ among females. We also performed the KruskalWallis $H$-test on CIRs from all regions in females and is found statistically significant for these regions in comparison to remaining administrative regions. The chi-square values $\left[\chi^{2}(12, \mathrm{~N}=143),(\mathrm{P}<0.01)\right]$ were calculated for $\mathrm{CC}\left(\chi^{2}=\right.$ $77.818)$ and $\mathrm{RC}\left(\chi^{2}=66.613\right)$. The lowest mean CIR was observed in Jazan for CC and RC (Figure 4A and B).

The ASIRs of CC and RC were reported from the SCR classified according to the year of diagnosis (Figure 5A and B). Overall, there was a small increase in the ASIRs in CC and RC. In 2013, the highest ASIR of CC was reported at 6.5 , and the lowest was at 4.8 females in 2007. Whereas, 2009, 2012, and 2013 were the years when the highest ASIR of RC was reported at 3.7 and the lowest ASIR of $\mathrm{RC}$ was reported in 2014 at 2.9. Furthermore, the mean ASIR of CC was at 5.6 and the mean ASIR of RC was at 3.4 (Figure $5 \mathrm{~A}$ and $\mathrm{B}$ ).

The mean ASIRs classified by the administrative region of Saudi Arabia for CC and RC were calculated 

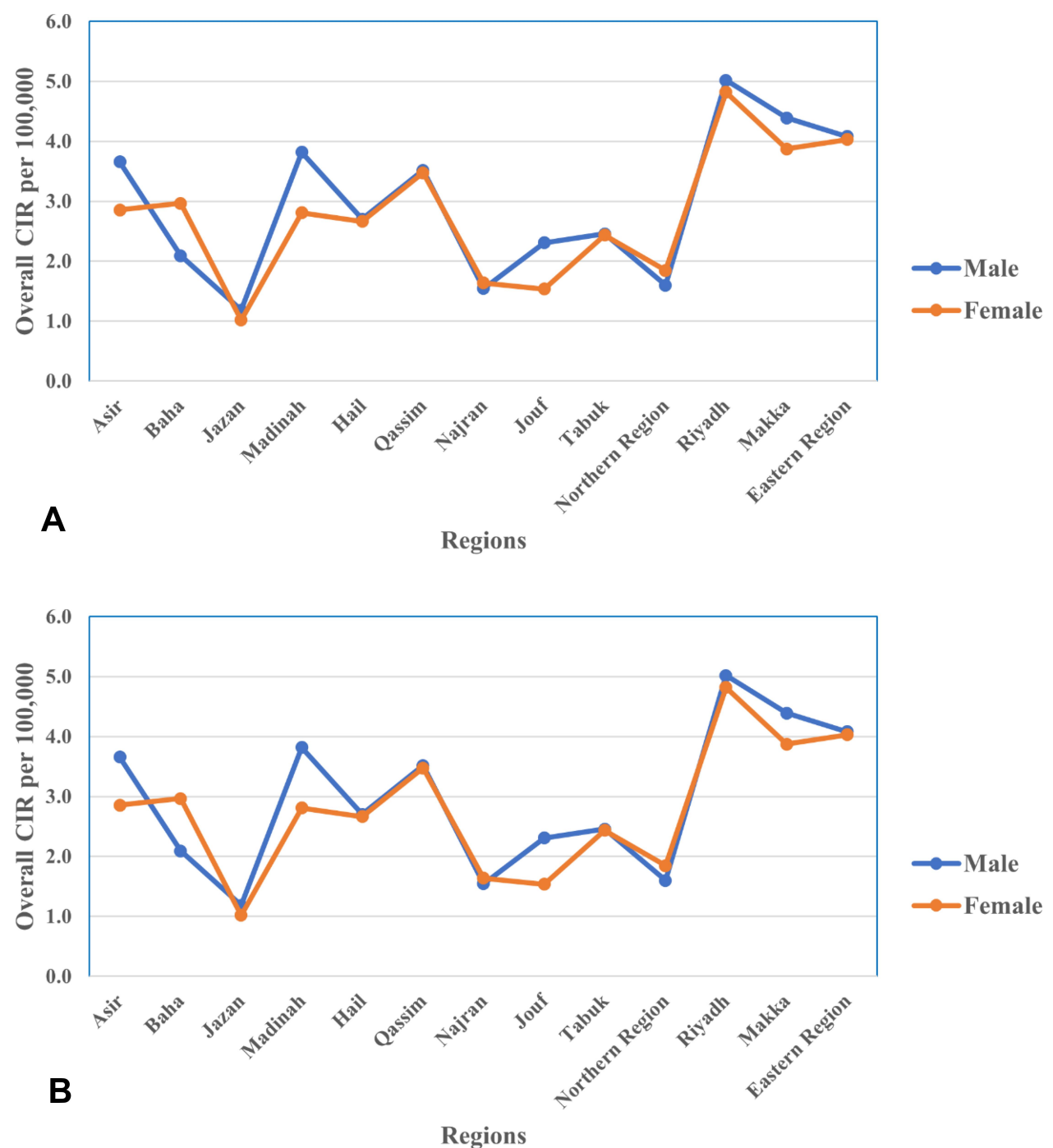

Figure 4 (A) Overall crude incidence rate (CIR) of colon cancer cases per 100,000 between males and females according to administrative regions during 2006 to 20I6. (B) Overall crude incidence rate (CIR) of rectum cancer cases per 100,000 between males and females according to administrative regions during 2006 to $20 \mathrm{I} 6$.

(Figure 6A and B). The highest mean ASIR for $\mathrm{CC}$ was reported from the regions of Riyadh and Makkah at 8.4, followed by Eastern Province at 6.9. Similarly, the highest mean ASIR for RC was reported from the region of Riyadh, followed by Eastern Province. We also performed the Kruskal-Wallis $H$-test on ASIRs from all regions in females and is found statistically significant for these regions in comparison to remaining administrative regions. The chi-square values $\left[\chi^{2}(12, \mathrm{~N}=143),(\mathrm{P}<0.01)\right]$ were calculated for $\mathrm{CC}\left(\chi^{2}=88.428\right)$ and $\operatorname{RC}\left(\chi^{2}=58.506\right)$. Alternatively, the lowest mean ASIRs of CC and RC were documented in Jazan (Figure 6A and B) (Supplementary Table 6. A, 6. B).

The inclusive distribution of the percentage of a stage of colorectal cancer in females was also reported to know that in what stage the cancer was diagnosed more frequently among females. We found that colorectal cancer was diagnosed more frequently at the regional stage (37.8\%), which was followed by a distant stage $(28.1 \%)$ and localized stage $(22 \%)$. It is also reported that colorectal cancer was diagnosed at an unknown stage in a lower percentage (12.1\%) (Figure 7B) (Supplementary Table 7. B).

\section{Discussion}

In all the administrative regions of Saudi Arabia, the crude incidence rates (CIRs) and age-standardized incidence rates (ASIRs) of colorectal cancer (CRC) cases are needed to critically be examined, updated, and thoroughly studied for understanding the disease better among the Saudi population. In this retrospective and descriptive study, we analyzed the trends of the CIRs and ASIRs of colon and rectum cancer. This detailed epidemiological analysis of 

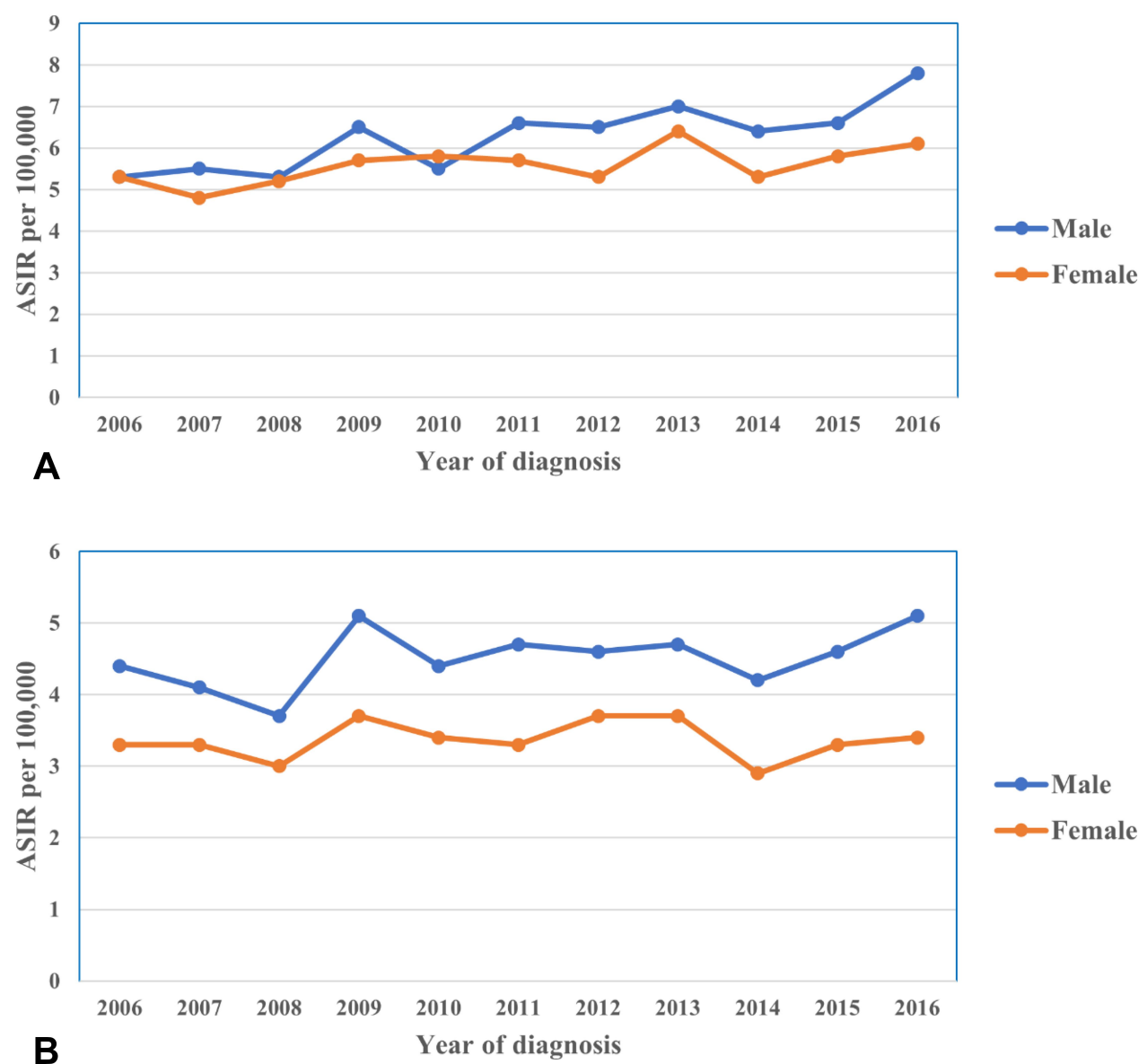

Figure 5 (A) Age-standardized incidence rate (ASIR) of colon cancer cases per 100,000 between males and females during 2006 to 2016. (B) Age-standardized incidence rate (ASIR) of rectum cancer cases per 100,000 between males and females during 2006 to 2016.

the spatial/temporal distribution of colon and rectal cancer among males and females in different administrative regions of Saudi Arabia is considered to be the first study based on the PubMed database. This study inspects the trend, real situation of CC and RC in the country, and explores the importance of this disease in Saudi Arabia's population.

A study was conducted showing that lifestyle factors such as physical inactivity, excess weight or obesity, and smoking causing a huge fraction of CRC cases among both genders in Saudi Arabia. Besides study also predicted that the cases would increase from 2025 to 2040 in a basic scenario of the constant prevalence of risk factors. However, a $5-10 \%$ reduction in the prevalence of each risk factor by every 5 years showed a decrease in the number of cases by 2040 among both genders. ${ }^{16}$ Here, we observed that the highest mean ASIRs for CRC among males as well as females, from 2006 to 2016, were reported in the regions of Riyadh, Makkah, and Eastern Province. The most probable explanation for these increase in ASIRs is that most of the population were greatly susceptible to the risk factors of $\mathrm{CC}$ and $\mathrm{RC}$ in comparison to other regions. Moreover, the effects of environmental factors, lifestyle changes, and genetic susceptibilities could be linked with this rise in ASIRs of CC and RC among males in Riyadh, Makkah, and Eastern Province. Therefore, there is a need for a detailed epidemiological investigation which will shed some light on major risk factors associated with the increase of ASIRs of CC and RC in the regions of Riyadh, Makkah, and Eastern Province. A possible reason for the high value of incidence rate could be the advanced healthcare facilities and accessibility. Other than this the probable causative factor to the increased incidence rate could be the presence of industries in these regions. ${ }^{17}$ Another possible reason that claimed to be a major risk factor is the deficiency of Vitamin D. ${ }^{18}$ It was reported that $83.6 \%$ of the Arabian population has Vit D deficiency. ${ }^{19}$ Besides $100 \%$ severe Vit D deficiency was observed in Saudi University students. ${ }^{20}$ We also observed that the Jazan region has the least mean ASIRs for CC and RC among males as well as 


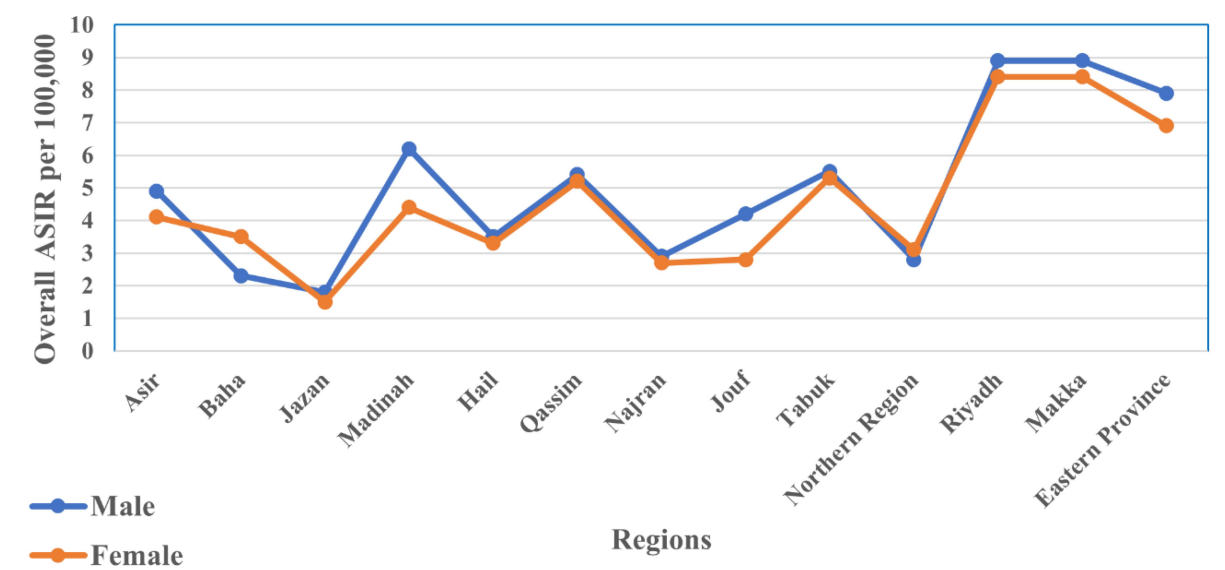

A

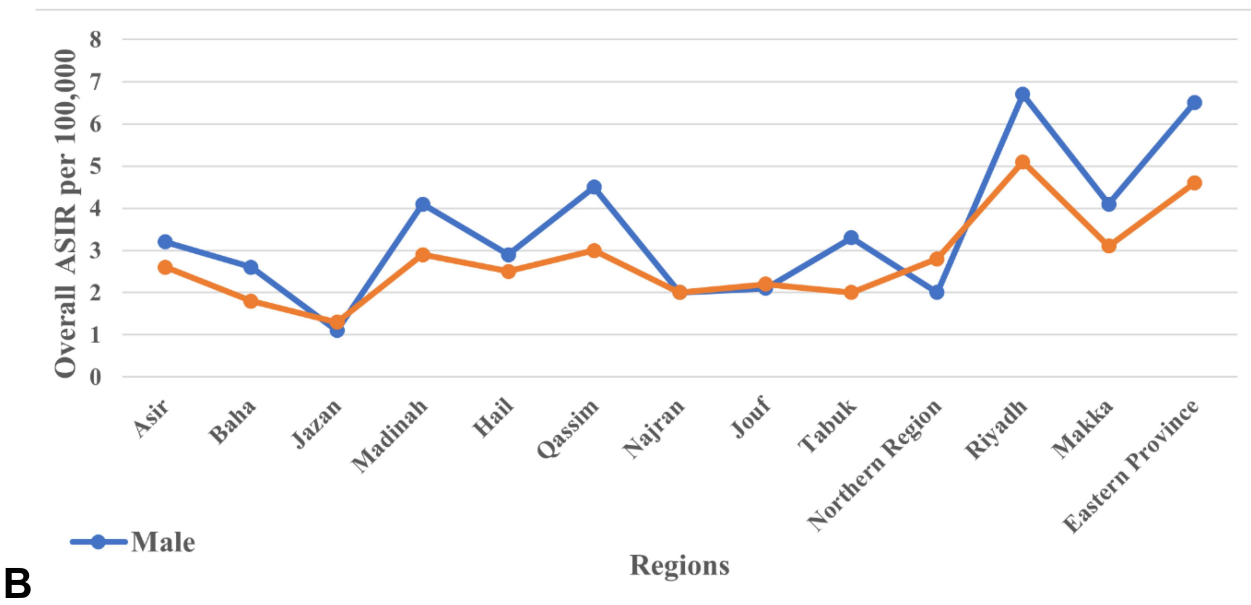

Figure 6 (A) Overall age-standardized incidence rate (ASIR) of colon cancer cases per 100,000 between males and females according to administrative regions during 2006 to 2016. (B) Overall age-standardized incidence rate (ASIR) of rectum cancer cases per 100,000 between males and females according to administrative regions during 2006 to 2016 .

among females, from 2006 to 2016. This could be due to exposure to some protecting aspects of the region's environment or other factors in comparison to regions with higher ASIRs. The probable reason could be the less industrialization, less western lifestyle adaptation or westernization, less healthcare facility and accessibility, less screening of $\mathrm{CRC}$ in these regions compared to high incidence regions. With a 35\% prevalence of obesity, Riyadh showed a highly affected region in contrast to Jazan which is at $2 \%$. Therefore, Riyadh showed significantly higher rates than other regions of Saudi Arabia. ${ }^{21}$ Analyzing these factors regarding CRC could be a key mechanism that could provide a better understanding of the disease as well as beneficial in decreasing its burden.

We also observed significant changes in the crude incidence rates (CIRs) and age-standardized incidence rates (ASIRs) of the colon as well as rectum cancers in both males and females in different administrative regions of Saudi Arabia between 2006 and 2016 (Tables 3 and 4). The most significant changes were reported in the region of Eastern Province with the highest CIR (4.4) and ASIR (5.5) for colon cancer in males and in the region of Jouf with the highest CIR (2.7) and ASIR (4.6) for rectal cancer in females. The Northern region was reported to be highest in ASIRs for colon cancer in females and rectal cancer in males. The regions of Baha and Asir were reported to be highest in CIRs for colon cancer in females and rectal cancer in males, respectively. Likewise, the least significant changes in CIRs were reported in the region of Jazan for colon cancer in males as well as in females and for rectal cancer in males, and the lowest increase in ASIR for colon cancer in females. The region of Makka is found to be with the least changes in ASIRs for rectal cancer in both males and females. Apart from these regions, Tabuk and Baha were reported with the least CIR for rectal cancer in females and ASIR for colon cancer in males, 
Overall \% Stage Distribution in Colo-Rectal Cancer in Males

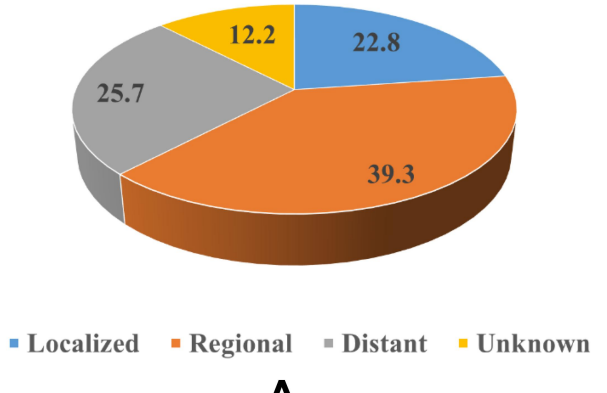

A

Overall \% Stage Distribution in Colo-Rectal Cancer in Females

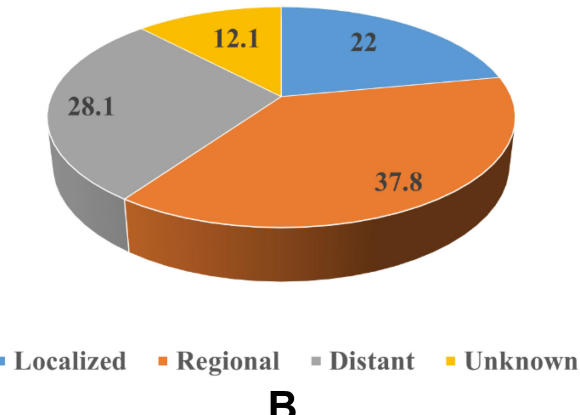

B

Figure 7 (A) Overall percentage stage distribution of colorectal cancer in males during 2006 to 2016. (B) Overall percentage stage distribution of colorectal cancer in females during 2006 to 2016 .

respectively. These trends indicate only an increase in CIRs and ASIRs of both cancers and the regions of Eastern Province, Northern region and Jouf are the frontrunners in the most significant changes of CIRs and ASIRs for both cancers from 2006 to 2016. Apart from these increases, some regions are also reported with a decrease in CIRs and ASIRs from 2006 to 2016; and Madinah, Hail, and Nazran are the primary regions that have a decrease in CIRs and/or ASIRs in both cancers among males and females.

A meta-analysis study showed that $20 \%$ to $30 \%$ of CRC risk was reduced by regular physical activity or exercise. ${ }^{22}$ Besides vitamins, folate, fiber diet aspirin, NSAIDs (nonsteroidal anti-inflammatory drugs) supplementation showed avert in the CRC development. ${ }^{23,24}$ Along with making better and healthy lifestyle, disease awareness and knowledge, ${ }^{25,26}$ reducing the age of CRC screening not only help in early diagnosis and prognosis but also reduces the incidence rate among the young population of Saudi Arabia under the age of 50 years which may burden the national healthcare system in the next decades. ${ }^{27-29}$ However, in the US by 2030 new cases were expected to increase among 20-49 years aged younger population. ${ }^{30}$ Recently a study shows that CRC is present in young women. Other than the threshold screening age, investment in healthcare systems, and cost-effective screening or treatment, the possible reason discussed was the lack of specialized care outside the major cities, lack of predictive diagnosis, and targeted anticipation. ${ }^{31}$ It is necessary to develop regional and national policies, guidelines, and multi-level diagnoses that could help in the reduction in the rate of incidence, mortality, and morbidity of CRC. ${ }^{32}$

This study is step-in anticipation of explaining the trends of colorectal cancer in Saudi Arabia and its administrative regions between the years from 2006 to 2016. The global scenario of colorectal cancer is reported to GLOBOCAN 2018, that the colon cancer is in fourth place and the rectum cancer is in eighth place in the world's most incident cancers as reported. ${ }^{33}$ The highest incidence of colon cancer is reported from Southern Europe, followed by Australia/ New Zealand, and Northern Europe. Whereas, Eastern Europe reported the highest incidence for rectal cancer, followed by Australia/New Zealand, and Eastern Asia. Hungary has the highest incidence of colorectal cancer in males while Norway has it in females. The mortality rate of colorectal cancer has also been reported to be highest in Saudi Arabia, Oman, and UAE among males, and Algeria, Belarus, Japan, Spain, and Portugal among females. ${ }^{34}$

\section{Conclusions}

This study indicated an increase in crude incidence rates and age-standardized incidence rates of colorectal cancer in the population of Saudi Arabia. The highest mean ASIRs of the colon and rectal cancers were reported in the regions of Riyadh, Makka, and Eastern Province among males and females, whereas the lowest mean ASIRs were reported in the regions of Jazan and Najran. The mean ASIR sex ratio was reported to be less than twice in males than females in Saudi Arabia which represents that colorectal cancer is more frequent in males than females but at a lower level. More studies will be needed to discern the roles of prospective aspects of colorectal cancer in the population of Saudi Arabia, which also could provide a better understanding of the disease as well as advantageous in decreasing its burden.

\section{Abbreviations}

GI, gastrointestinal; CRC, colorectal cancer; CC, colon cancer; RC, rectum cancer; CIR, crude incidence rate; AIR, age-specific incidence rate; ASIR, age-standardized incidence rate; ASMR, age-standardized mortality rate. 


\section{Disclosure}

The author declares that they have no conflicts of interest in this work.

\section{References}

1. Ferlay J, Ervik M, Lam F, et al. Global cancer observatory: cancer today. Lyon, France: International Agency for Research on Cancer. Available from: https://gco.iarc.fr/today. Accessed May 25, 2020.

2. Haggar FA, Boushey RP. Colorectal cancer epidemiology: incidence, mortality, survival, and risk factors. Clin Colon Rectal Surg. 2009;22 (4):191-197. doi:10.1055/s-0029-1242458

3. Ferlay J, Colombet M, Soerjomataram I, et al. Estimating the global cancer incidence and mortality in 2018: GLOBOCAN sources and methods. Int $J$ Cancer. 2019;144(8):1941-1953. PMID: 30350310. doi:10.1002/ijc.31937

4. Arafa MA, Farhat K. Colorectal cancer in the Arab World-screening practices and future prospects. Asian Pac J Cancer Prev. 2015;16 (17):7425-7430. doi:10.7314/apjcp.2015.16.17.7425

5. Keum N, Giovannucci E. Global burden of colorectal cancer: emerging trends, risk factors and prevention strategies. Nat Rev Gastroenterol Hepatol. 2019;16(12):713-732. doi:10.1038/s41575019-0189-8

6. Howlader N, Noone AM, Krapcho M, et al. editors. SEER cancer statistics review, 1975-2017. Bethesda, MD: National Cancer Institute; 2019. Available from: https://seer.cancer.gov/csr/1975 2017/. Accessed April, 2020.

7. Arnold M, Abnet CC, Neale RE, et al. Global burden of 5 major types of gastrointestinal cancer. Gastroenterology. 2020. doi:10.1053/ j.gastro.2020.02.068

8. Chaudhri E, Fathi W, Hussain F, Hashmi SK. The increasing trends in cases of the most common cancers in Saudi Arabia. J Epidemiol Glob Health. 2020. doi:10.2991/jegh.k.200515.001

9. Alqarni SSM. A review of prevalence of obesity in Saudi Arabia. Int J Obes Eat Disord. 2016;2(2). doi:10.21767/2471-8203.100025

10. Fayadh MH. Colorectal cancer in Abu Dhabi, UAE - initial data 2014-2016. Colorectal Cancer. 2016;2(3). doi:10.21767/24719943.100024

11. Alghamdi IG, Alghamdi MS. The incidence rate of liver cancer in saudi arabia: an observational descriptive epidemiological analysis of data from the Saudi Cancer Registry (2004-2014). Cancer Manag Res. 2020;12:1101-1111. doi:10.2147/CMAR.S232600

12. Aggarwal R, Ranganathan P. Study designs: part 2 - descriptive studies. Perspect Clin Res. 2019;10(1):34. doi:10.4103/picr. PICR_154_18

13. Saudi cancer registry: annual reports. Available from: https://nhic. gov.sa/en/eServices/Pages/TumorRegistration.aspx. Accessed May $25,2020$.

14. Alsanea N, Almadi MA, Abduljabbar AS, et al. National guidelines for colorectal cancer screening in Saudi Arabia with strength of recommendations and quality of evidence. Ann Saudi Med. 2015;35 (3):189-195. doi:10.5144/0256-4947.2015.189

15. Amin MB, Edge S, Greene F, et al. eds. AJCC Cancer Staging Manual. 8th ed. Springer International Publishing; 2017. Available from: https:/www.springer.com/gp/book/9783319406176. Accessed October 21, 2020.

16. Al-Zalabani A. Preventability of colorectal cancer in Saudi Arabia: fraction of cases attributable to modifiable risk factors in 2015-2040. Int J Environ Res Public Health. 2020;17(1):320. doi:10.3390/ ijerph 17010320
17. Al-Ahmadi K, Al-Zahrani A. NO (2) and cancer incidence in Saudi Arabia. Int J Environ Res Public Health. 2013;10(11):5844-5862. doi:10.3390/ijerph10115844

18. Feldman D, Krishnan AV, Swami S, Giovannucci E, Feldman BJ. The role of vitamin $\mathrm{D}$ in reducing cancer risk and progression. Nat Rev Cancer. 2014;14(5):342.

19. Hussain AN, Alkhenizan AH, El Shaker M, Raef H, Gabr A. Increasing trends and significance of hypovitaminosis D a population-based study in the Kingdom of Saudi Arabia. Arch Osteoporos. 2014;9(1):190.

20. Al-Elq AH. The status of Vitamin D in medical students in the preclerkship years of a Saudi medical school. J Family Community Med. 2012;19(2):100.

21. Saad MA. A review of prevalence of obesity in Saudi Arabia. J Prevalence Obes Saudi Arabia. 2016;2:2-25.

22. Chan AT, Giovannucci EL. Primary prevention of colorectal cancer. Gastroenterology. 2010;138(6):2029-43.e10. doi:10.1053/j.gastro. 2010.01.057

23. Drew DA, Cao Y, Chan AT. Aspirin and colorectal cancer: the promise of precision chemoprevention. Nat Rev Cancer. 2016;16(3):173.

24. Heine-Bröring RC, Winkels RM, Renkema J, et al. Dietary supplement use and colorectal cancer risk: a systematic review and metaanalyses of prospective cohort studies. Int $J$ Cancer. 2015;136 (10):2388-2401. doi:10.1002/ijc.29277

25. Alnuwaysir M, Baral N, Alhadhari H. Colorectal cancer awareness and attitude among adult, Al-Dammam, Saudi Arabia. Adv Cancer Prev. 2016;1(04):117. doi:10.4172/2472-0429.1000117

26. Al-Hajeili M, Abdulwassi HK, Alshadadi F, Alqurashi L, Idriss M, Halawani L. Assessing knowledge on preventive colorectal cancer screening in Saudi Arabia: a cross-sectional study. J Family Med Prim Care. 2019;8(10):3140-3146. doi:10.4103/jfmpc.jfmpc_508_19

27. Bishehsari F, Mahdavinia M, Vacca M, Malekzadeh R, MarianiCostantini R. Epidemiological transition of colorectal cancer in developing countries: environmental factors, molecular pathways, and opportunities for prevention. World J Gastroenterol. 2014;20 (20):6055. doi:10.3748/wjg.v20.i20.6055

28. Guraya SY. The prevalence and evolving risk factors for colorectal cancer in the Arab World. Biomed Pharmacol J. 2018;11 (4):1773-1780. doi:10.13005/bpj/1548

29. Aljumah AA, Aljebreen AM. Policy of screening for colorectal cancer in Saudi Arabia: a prospective analysis. Saudi J Gastroenterol. 2017;23(3):161-168. doi:10.4103/sjg.sjg_468_16.

30. Siegel RL, Fedewa SA, Anderson WF, et al. Colorectal cancer incidence patterns in the United States, 1974-2013. J Natl Cancer Inst. 2017;109(8). doi:10.1093/jnci/djw322.

31. Alsanea N, Abduljabbar AS, Alhomoud S, Ashari LH, Hibbert D, Bazarbashi S. Colorectal cancer in Saudi Arabia: incidence, survival, demographics and implications for national policies. Ann Saudi Med. 2015;35(3):196-202. doi:10.5144/0256-4947.2015.196

32. Alyabsi M, Alhumaid A, Allah-Bakhsh H, et al. Colorectal cancer in Saudi Arabia as the proof-of-principle model for implementing strategies of predictive, preventive, and personalized medicine in healthcare. EPMA J. 2020;11:119-131.

33. Rawla P, Sunkara T, Barsouk A. Epidemiology of colorectal cancer: incidence, mortality, survival, and risk factors. Prz Gastroenterol. 2019;14(2):89-103. doi:10.5114/pg.2018.81072

34. Bray F, Ferlay J, Soerjomataram I, Siegel RL, Torre LA, Jemal A. Global cancer statistics 2018: GLOBOCAN estimates of incidence and mortality worldwide for 36 cancers in 185 countries. $C A$ Cancer J Clin. 2018;68(6):394-424. doi:10.3322/caac.21492 


\section{Publish your work in this journal}

The International Journal of General Medicine is an international, peer-reviewed open-access journal that focuses on general and internal medicine, pathogenesis, epidemiology, diagnosis, monitoring and treatment protocols. The journal is characterized by the rapid reporting of reviews, original research and clinical studies across all disease areas. The manuscript management system is completely online and includes a very quick and fair peer-review system, which is all easy to use. Visit http://www.dovepress.com/ testimonials.php to read real quotes from published authors. 